\title{
The pharmacology course for preclinical students using team-based learning
}

\author{
Do-Hwan Kim', Jung-Ho Lee ${ }^{2}$ and Soon Ae Kim² \\ ${ }^{1}$ Department of Medical Education, Hanyang University College of Medicine, Seoul, and ${ }^{2}$ Department of \\ Pharmacology, Eulji University School of Medicine, Daejeon, Korea
}

Purpose: A pharmacology course in undergraduate medical education aims to enable students to cultivate the ability of applying drugs in the clinical context using basic scientific knowledge. Although team-based learning could be a useful approach, the literature on pharmacology education using team-based learning is limited. This study aims to evaluate the effectiveness of a pharmacology course using team-based learning.

Methods: We developed an "integrated clinical pharmacology" course for first-year medical students. All 49 students enrolled in the course. Individual and group scores were recorded for each session, and a post-course survey was conducted after the course. We compared the performance of the current class to that of a previous class based on scores in a nationwide test conducted at the end of every year.

Results: The reactions of the students were generally positive, with the exception of their perception of the preparatory burdens for the individual test. Throughout the team-based learning sessions, the achievement at the group level was significantly higher than at the individual level. In the nationwide test, however, when we divided students into high and low achiever groups, only the low achievers demonstrated significant improvement compared to the cohort from the previous year.

Conclusion: The study demonstrates that team-based learning could be an effective way of teaching pharmacology to medical students in the preclinical stage. Although most of the students were actively engaged regardless of their preparedness, low-achieving students in particular seemed to gain more benefits than high achievers regarding the acquisition of knowledge.

Key Words: Pharmacology, Team-based learning, Program evaluation

\section{Introduction}

Pharmacology is one of the core courses forming the foundation of a medical curriculum. Considering the medical student's anticipated role as a physician, in a pharmacology course, practicing active decision-making when selecting appropriate drugs should be more emphasized than the passive transmission of information to students through didactic lectures. That is, the ultimate purpose of pharmacology education should be cultivation of the ability to apply drugs in a clinical context, based on a scientific mechanism which requires the integration of basic and clinical medical sciences [1] This "integration," however, is not as straightforward as it seems. Although medical schools claim an "integrated
Received: October 28, 2019 • Revised: December 12, 2019 • Accepted: January 2, 2020 Corresponding Author: Soon Ae Kim (https://orcid.org/0000-0002-9831-0511) Department of Pharmacology, Eulji University School of Medicine, 77 Gyeryong-ro 771beon-gil, Jung-gu, Daejeon 34824, Korea

Tel: +82.42.259.1672 Fax: +82.42.259.1677 email: sakim@eulji.ac.kr
Korean J Med Educ 2020 Mar; 32(1): 35-46. https://doi.org/10.3946/kjme.2020.151

eISSN: 2005-7288

(C) The Korean Society of Medical Education. All rights reserved. This is an open-access article distributed under the terms of the Creative Commons Attribution Non-Commercial License (http:// creativecommons.org/licenses/by-nc/3.0/), which permits unrestricted non-commercial use, distribution, and reproduction in any medium, provided the original work is properly cited. 
curriculum" as one of their core curricular strategies, integrated understanding, a cognitive activity of the learner, is less likely to occur by merely increasing the temporal proximity (e.g., rearrangement of lectures) of contents in basic and clinical science [2]. Rather, the evidence shows that integration of content at the session level, rather than at the course or curriculum level, has a more meaningful impact [3]. Therefore, team-based learning (TBL), which encourages application and integration as well as the acquisition of knowledge within a single session through student group work [4], could be a promising approach for pharmacology teaching.

Nevertheless, the way the basic sciences are currently taught in the medical curriculum still centers on individual or departmental didactic lectures [5]. As such, several practical barriers exist to implementation of TBL. For example, additional faculty development would be necessary for faculty members unfamiliar with TBL [6]. Sometimes, students are even reluctant to engage in classes designed to foster active learning, which becomes a significant challenge for teaching staff [7]. As a result of "scheduling conflicts" and "a series of compromises" [8], TBL often ends up being an ancillary part of a single course for specific topics [9], despite an initial intention to implement a full TBL-based course.

Even after implementation, because the manner in which TBL is implemented is critical to its success $[6,10]$, there exist some uncertainties concerning its effectiveness. First, the learner's reaction to TBL is equivocal [11]. In the preclinical years, in particular, students tend to evaluate TBL facilitators less positively than in clinical years [12] despite the fact that the approach is employed at a higher frequency [9]. Additional investigation may also be required to show how student reactions change when they repeatedly experience TBL and become accustomed to it [11]. Second, whereas the existing literature is generally positive regarding its effectiveness for knowledge retention, many reported knowledge-based learning outcomes are restricted to an immediate exam score within the course [11]. That is, relatively less is known about the effectiveness of TBL over the longer term, following the completion of a course. Furthermore, a few studies suggest that even this positive effect on learning may not be consistent, depending on a student's previous academic achievement level [13].

Thus far, however, the literature on TBL in the context of pharmacological education has been limited to a small number concerning the countries where the studies were conducted [11,14-16]. For example, in South Korea, although more than a decade has passed since TBL was introduced to the field of medical education, very few studies have evaluated or reported the effectiveness of any course [17,18], let alone pharmacological education. Provided that the same educational interaction may have variable effectiveness depending on contextual factors [19], more studies in various contexts including course duration, discipline, and institution, are needed. In terms of learning, evaluation beyond immediate retention would give a broader picture of the level of improvement maintained by virtue of the TBL course.

This study aimed to evaluate the effectiveness of a pharmacology course that used TBL as a primary pedagogical approach in a medical school. For this purpose, as an immediate outcome, we first investigated students' reactions and improvement of learning through a TBL-based pharmacology course. Subsequently, as a delayed learning outcome, we examined whether the improvement was maintained in a separate nationwide test conducted about a month following the end of the course. 


\section{Methods}

\section{Research design}

An overview of the study design based on the research questions is shown in Fig. 1. A comparison between the performance of the 2017 and 2018 cohort was a quasi-experimental design, using the Comprehensive Basic Medical Sciences Examination (CBMSE, gichouihak-jonghap-pyeongga in Korean) as a post-test. We considered only the 2017 cohort as a control group, because the grading system changed from a pass-fail to a letter-based (A-F) system in 2017.

\section{Setting}

Eulji University School of Medicine (EUSOM) operates a 6-year undergraduate medical curriculum. As a premedical curriculum, basic science and liberal arts courses are primarily taught during the first and second years. During the third (M3) and fourth (M4) years, students are taught basic medical and clinical subjects as

Fig. 1. Conceptual Framework about Research Design

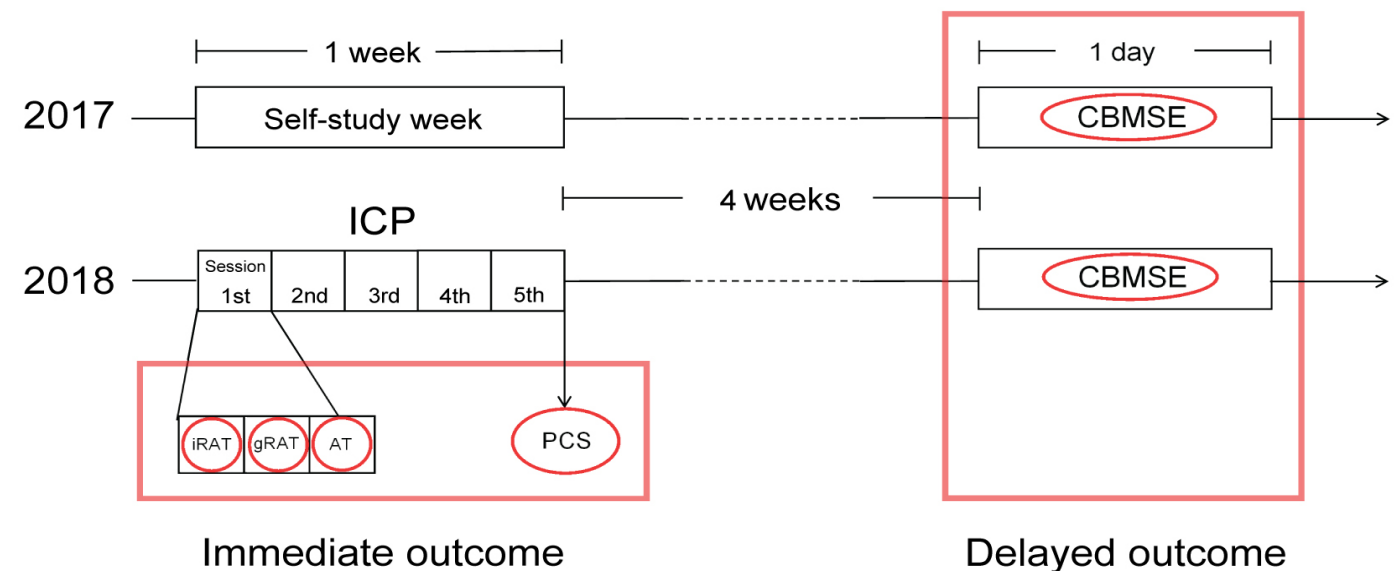

O: Data collection

ICP: Integrated clinical pharmacology, PCS: Post-course survey, CBMSE: Comprehensive Basic Medical Sciences Examination, iRAT: Individual Readiness Assurance Test, gRAT: Group Readiness Assurance Test, AT: Advanced Test.

\begin{tabular}{|c|c|c|c|c|}
\hline Semester & Name of the courses & Description (major contents) & Credits & Teaching hours $|\%|$ \\
\hline \multirow[t]{2}{*}{ 1st } & Basic neuroscience & $\begin{array}{l}\text { Local anesthetic pharmacology central nervous system } \\
\text { pharmacology }\end{array}$ & 7.5 & $23(19.8)$ \\
\hline & Understanding human responses & $\begin{array}{l}\text { Pharmacokinetics pharmacodynamics autonomic nervous } \\
\text { system pharmacology cardiovascular pharmacology } \\
\text { endocrine pharmacology }\end{array}$ & 9 & $58(50.0)$ \\
\hline \multirow[t]{6}{*}{ 2nd } & Oncology & Cancer pharmacology & 2 & $2(1.7)$ \\
\hline & Pathology of human body & Non-steroidal anti-inflammatory drugs & 1.5 & $2(1.7)$ \\
\hline & Infection and defense mechanism & Antimicrobial pharmacology & 5 & $18(15.5)$ \\
\hline & Genetics in medicine & Pharmacogenomics & 3.5 & $13(11.2)$ \\
\hline & Integrated clinical pharmacology & $\begin{array}{l}\text { Team-based learning of pharmacologic knowledge } \\
\text { previously learned in first and second semesters }\end{array}$ & 1 & - \\
\hline & $\begin{array}{l}\text { Comprehensive basic medical } \\
\text { sciences examination }\end{array}$ & $\begin{array}{l}\text { Nation-wide examination for major basic medical science } \\
\text { disciplines including pharmacology }\end{array}$ & 1 & - \\
\hline
\end{tabular}

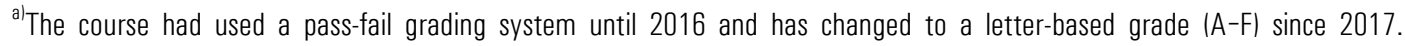


integral courses. The curricula of the final 2 years, the fifth and sixth years, are centered on the clinical clerkship.

In the M3 curriculum, pharmacology has been taught in a dispersed manner throughout the year (Table 1). Understanding human responses (UHR), a multidisciplinary integrated course, makes up the largest portion and deals with the main theoretical part of pharmacology. While the preclinical (i.e., M3 and M4) curricula have been maintained without change in recent years, integrated clinical pharmacology (ICP) was newly introduced for M3 students in 2018. ICP is a 1-week block-type course, conducted from November 19 to 23. Despite the addition of the ICP course, there was no change in the total number of education weeks in the M3 year because it replaced a week that was previously left open for students to prepare for their final exams in the second semester.

\section{Team-based learning in integrated clinical pharmacology}

All M3 students in 2018 enrolled in ICP. The course was largely divided into morning and afternoon sessions. In the morning, topic areas not covered in the first semester such as ethics of clinical trials, overthe-counter medicine, and the development of new pharmaceuticals, were taught in a didactic lecture format. Afternoon sessions were operated based on TBL. There was a 1-hour orientation concerning the overall process of TBL at the beginning of the course. For the TBL sessions, the topics were divided into five areas: antibiotics and anti-cancer drugs; pharmacokinetics and pharmacodynamics; endocrine systems; circulatory systems; and central nervous systems.

In TBL, 49 students were divided into nine groups of five or six. Each group was assigned at random, other than taking into account the gender ratio. The overall process of TBL followed general guidelines, namely, advanced preparation, the individual Readiness Assurance Test (iRAT), group Readiness Assurance Test (gRAT), and an application exercise (which we referred to as an Advanced Test [AT]). Before class, for advanced preparation, we guided students to review the materials previously distributed and taught for UHR in the first semester. In class, students first took the iRAT for 10 minutes, then proceeded to intra-group discussions to solve identical questions (gRAT), using any reference materials, including textbooks or internet search. Then, time for inter-group discussion was given to justify or elaborate the rationale of the group's answers item by item. This inter-group discussion lasted about 60 to 90 minutes. Finally, the AT, as a group test, proceeded with a similar sequence of gRAT for about 60 minutes. All TBL sessions were facilitated by more than two professors majoring in pharmacology. Depending on the topic, clinical faculty members also participated as facilitators to provide immediate feedback or as lecturers to give mini lectures to sum up the work.

Each iRAT/gRAT comprised 10 multiple choice questions. All items included clinical vignettes for session topic, and options included a list of related drugs. Students were asked to select the most appropriate drug. Students earned two points for each correct item, with no penalty for incorrect answers. For the iRAT/gRAT, to ensure the use of high-quality items of clinical significance, we selected items among the item pools of the CBMSE from 2010 to 2017. We included five items for the AT based on the recommendations of faculty members in the related clinical field to ensure a higher difficulty than iRAT/gRAT. For the AT, students earned four points for each correct item. The items were chosen among item pools of the Comprehensive Clinical Medical Sciences Examination (CCMSE, a nationwide test that covers both basic and clinical contents, imsang- 
uihak-jonghap-pyeongga in Korean) and the Korean Medical Licensing Examination (KMLE) of the same period. However, we did not inform students about the item pools (i.e., CBMSE, CCMSE, and KMLE) beforehand to prevent test-targeted pre-class preparation.

\section{Data acquisition}

\section{1) $\mathrm{TBL}$}

We collected test scores, peer evaluation scores, and post-course survey results. The test scores included iRAT, gRAT, and AT scores, and each took into account $20 \%$ of the total ICP course scores. Peer evaluation occupied $10 \%$ of the total score. For peer evaluation, we asked students to evaluate other group members and to select best (over than 12 score) and worst members (less than 8 score) based on their communication skills, problem-solving abilities, and participation after finishing all five sessions.

A post-course survey was conducted anonymously at the end of the course. The content of the survey, which comprised 12 five-point Likert scale items, encompasses perceived utility, appropriateness of facilities, sufficiency of scheduled time, quality of peer teaching, use of learning resources, overall satisfaction, and so forth. We also included an open-ended question for any comments or suggestions. To ensure content validity, the questions were first developed by the director of the ICP course and then reviewed by facilitators and a medical education specialist. The Cronbach's $\alpha$ of the collected responses was 0.912 .

\section{2) CBMSE}

The CBMSE is a nationwide test covering major basic medical subjects including anatomy, biochemistry, physiology, pharmacology, pathology, and parasitology. The exam is conducted at the end of December every year, and is taken by about 3,500 first- and/or second-year medical students. Around $70 \%$ of examinees are first-year medical students. For 2017 and 2018, the number of total examinees in the first year of their medical courses were 2,333 and 2,563, respectively.

In EUSOM, M3 students, who correspond to the first-year medical students of other schools, take the test. In 2017 and 2018, all M3 students took the CBMSE (hereinafter referred to as the 2017M3 and 2018M3 cohort, respectively). The CBMSE scores were used to compare differences in academic achievement in pharmacology before and after the introduction of ICP. In consideration of the year-to-year differences in CBMSE item difficulty, we used percentile rank scores among same-year test-takers instead of the raw scores of each student.

\section{Data analysis}

Descriptive analysis was performed for the postcourse survey and test results. Comments collected from the open-ended question of the post-course survey were analyzed in accordance with the general procedure of structural content analysis [20]. For the test results, the correlation between scores was further examined at the individual or group level. To compare differences in academic performance in pharmacology before and after the implementation of ICP, we performed an independent sample t-test between 2017M3 and 2018M3 for all CBMSE subject grades, including pharmacology. In addition, we divided students into two groups - high and low achievers based on the median UHR score, and compared the differences using an independent sample t-test to examine the effect of TBL according to the level of previous academic achievement. This study received an instituional review board review waiver (EU19-85) and informed consent was not obtained from all individual participants included in the study. 


\section{Results}

gender, achievement in the UHR course, or percentile rank score on the CBMSE (Table 2).

\section{Post-course survey}

\section{Students' characteristics}

All 49 students enrolled in the course. Of the total, 73.5\% were male, and their average percentile rank score on the CBMSE was 43.2. There were no significant differences in major demographic characteristics between the 2017M3 and 2018M3 cohorts such as age,

Students' responses to other factors were generally positive, with median values of 4 or 5 and a range of between 3.77 and 4.43 (Table 3). However, the students perceived the iRATs level of difficulty (3.16 out of 5) most negatively among the various components of the survey. In the open-ended questionnaire, the most

Table 2. Students' Characteristics

\begin{tabular}{|c|c|c|c|}
\hline Characteristic $^{\text {al }}$ & $2017 \mathrm{M} 3(\mathrm{~N}=43)$ & $2018 \mathrm{M} 3(N=49)$ & Total $(N=92)$ \\
\hline TBL syllabus for pharmacology ${ }^{\text {b) }}$ & None & ICP (1-week TBL course) & \\
\hline \multicolumn{4}{|l|}{ Gender } \\
\hline Male & $25(58.1)$ & $36(73.5)$ & $61(66.3)$ \\
\hline Female & $18(41.9)$ & $13(26.5)$ & 31 (33.7) \\
\hline Age $(y r)$ & $23.0 \pm 2.30(20-33)$ & $22.7 \pm 1.68(21-28)$ & $22.8 \pm 1.99(20-33)$ \\
\hline Total score of UHR & $74.3 \pm 7.70(58.7-91.7)$ & $71.7 \pm 10.00(38.0-95.0)$ & $72.9 \pm 9.05(38.0-95.0)$ \\
\hline Percentile rank of CBMSE & $45.2 \pm 28.8(1.93-98.3)$ & $43.2 \pm 27.8(1.05-94.4)$ & $44.1 \pm 28.1(1.05-98.3)$ \\
\hline
\end{tabular}

Data are presented as number $(\%)$ or mean \pm standard deviation (range).

TBL: Team-based learning, ICP: Integrated clinical pharmacology, UHR: Understanding human responses, CBMSE: Comprehensive basic medical sciences examination.

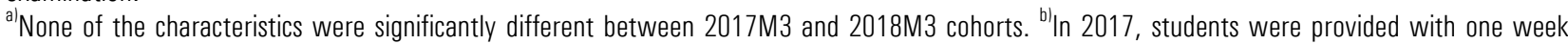
for self-study, without any didactic instruction. This one week was replaced by ICP-a one-week TBL course in clinical pharmacology.

\begin{tabular}{|c|c|c|c|}
\hline Type of question & Contents & Value & Median \\
\hline \multirow[t]{12}{*}{$\begin{array}{l}\text { Likert-scale }^{\text {al }} \\
\text { items }\end{array}$} & $\begin{array}{l}\text { The difficulty of iRAT was appropriate considering my preparedness and level of related } \\
\text { knowledge. }\end{array}$ & $3.16 \pm 1.20$ & 3 \\
\hline & The quality of teaching and learning among students was high. & $3.77 \pm 1.04$ & 4 \\
\hline & It is desirable to apply TBL to other subjects. & $3.82 \pm 1.22$ & 4 \\
\hline & Overall, TBL was useful to learn clinical pharmacology. & $3.94 \pm 1.07$ & 4 \\
\hline & Knowledge acquired through group discussion was extensive. & $3.96 \pm 0.91$ & 4 \\
\hline & Learning climate within the group was largely supportive. & $4.04 \pm 0.89$ & 4 \\
\hline & Group members were active in teaching each other. & $4.12 \pm 0.83$ & 4 \\
\hline & Group members were actively participating for most of the time. & $4.16 \pm 0.99$ & 4 \\
\hline & Time was sufficiently given for enough amount of discussion. & $4.24 \pm 0.90$ & 4 \\
\hline & Diverse learning materials were used to solve given problems. & $4.31 \pm 0.82$ & 5 \\
\hline & All group members collaborated efficiently. & $4.33 \pm 0.69$ & 4 \\
\hline & The place was appropriate for discussion & $4.43 \pm 0.76$ & 5 \\
\hline \multirow{3}{*}{$\begin{array}{l}\text { Open-ended } \\
\text { questions }\end{array}$} & It was difficult to comprehend clinical concepts. & $8 / 27(29.6)$ & - \\
\hline & Undertaking peer evaluation was troublesome. & $6 / 27(22.2)$ & - \\
\hline & Morning sessions needed to be more aligned with TBL sessions in the afternoon. & $6 / 27(22.2)$ & - \\
\hline
\end{tabular}

Data are presented as mean \pm standard deviation or number $(\%)$.

TBL: Team-based learning, iRAT: Individual Readiness Assurance Test.

a) 1: Strongly disagree, 2: Disagree, 3: Neutral, 4: Agree, 5: Totally agree. 
frequent answers were difficulty comprehending clinical knowledge (29.6\%, eight of 27 answers), difficulty conducting peer evaluation (22.2\%, six of 27 answers), and demand for more alignment within the course (22.2 $\%$, six of 27 answers).

\section{Team-based learning test results}

For each group, the gRAT scores were significantly improved over those of the iRAT (Table 4). The mean gRAT score was almost double that of the mean iRAT score (iRAT: 9.04 and gRAT: 18.00). Although the mean AT score was lower than the gRAT, students also demonstrated enhanced performance in AT over iRAT, with nine groups attaining an average of 16.0 points. At the group level, the average iRAT score of each group member showed significant correlation with the group's gRAT score but not with its AT score. By contrast, at the individual level, iRAT scores were not significantly correlated with peer evaluation scores.

\section{Impact on Comprehensive Basic Medical Sciences Examination pharmacology score}

When comparing the percentile rank score of CBMSE among all 2017M3 and 2018M3 cohorts, there was no significant difference in the total score. Similarly, for seven subjects, we could not find any significant change

Table 4. Student Assessment Results in TBL and Their Correlations (Individual and Group Level)

\begin{tabular}{|c|c|c|c|c|c|c|c|}
\hline \multirow{2}{*}{ Classification } & \multirow{2}{*}{ Category } & \multirow{2}{*}{$\begin{array}{l}\text { Mean } \pm \text { standard } \\
\text { deviation }\end{array}$} & \multicolumn{2}{|c|}{ Individual level } & \multicolumn{3}{|c|}{ Group level } \\
\hline & & & iRAT & Peer evaluation & iRAT & gRAT & AT \\
\hline \multirow[t]{2}{*}{ Individual level } & $\mathrm{iRAT}^{\mathrm{al}}$ & $9.06 \pm 2.10$ & - & $\begin{array}{c}-0.079 \\
(p=0.591)\end{array}$ & & & \\
\hline & Peer evaluation & $9.96 \pm 1.45$ & & - & & & \\
\hline \multirow[t]{3}{*}{ Group level $\left.\right|^{b)}$} & $i R A T^{c \mid}$ & $9.04 \pm 0.89$ & & & & $\begin{array}{c}0.710 \\
(p=0.032)\end{array}$ & $\begin{array}{c}0.145 \\
(p=0.709)\end{array}$ \\
\hline & gRAT & $18.0 \pm 1.00$ & & & & - & $\begin{array}{c}0.400 \\
(p=0.286)\end{array}$ \\
\hline & AT & $16.0 \pm 2.00$ & & & & & - \\
\hline
\end{tabular}

TBL: Team-based learning, iRAT: Individual Readiness Assurance Test, gRAT: Group Readiness Assurance Test, AT: Advanced Test.

${ }^{a l}$ The iRAT score of each student. ${ }^{b}$ Differences between iRAT, gRAT, and AT scores were significant $(F=103.234, p<0.001)$. Post hoc analysis (Scheffe's test) showed significant difference among three scores (iRAT $<$ AT $<$ gRAT). c) The average iRAT scores for each group ranged between 7.68 and 10.4 points, with a median score of 9.00 . There was no statistically significant difference among average iRAT scores of nine groups $(p=0.494)$.

Table 5. Percentile Rank Scores of Comprehensive Basic Medical Sciences Examination of M3 Cohorts in 2017 and 2018

\begin{tabular}{|c|c|c|c|c|c|c|c|c|c|}
\hline \multirow[b]{2}{*}{ Subjects } & \multicolumn{3}{|c|}{ Total (low achievers+high achievers) } & \multicolumn{3}{|c|}{ Low achievers" } & \multicolumn{3}{|c|}{ High achievers ${ }^{\text {al }}$} \\
\hline & $\begin{array}{c}2017 \\
(N=43)\end{array}$ & $\begin{array}{c}2018 \\
(N=49)\end{array}$ & $p$-value ${ }^{b l}$ & $\begin{array}{c}2017 \\
(\mathrm{~N}=22)\end{array}$ & $\begin{array}{c}2018 \\
(N=25)\end{array}$ & $p$-value ${ }^{b l}$ & $\begin{array}{c}2017 \\
(\mathrm{~N}=21)\end{array}$ & $\begin{array}{c}2018 \\
(N=24)\end{array}$ & $p$-value ${ }^{b l}$ \\
\hline Anatomy & $59.3 \pm 26.6$ & $55.4 \pm 27.9$ & 0.498 & $47.1 \pm 22.1$ & $52.6 \pm 27$ & 0.451 & $72.1 \pm 25.3$ & $58.4 \pm 29$ & 0.100 \\
\hline Physiology & $49.1 \pm 29.4$ & $48.9 \pm 26.4$ & 0.963 & $41.8 \pm 28$ & $49.2 \pm 28.1$ & 0.372 & $56.9 \pm 29.6$ & $48.6 \pm 25.2$ & 0.316 \\
\hline Biochemistry & $39.1 \pm 24.7$ & $38.4 \pm 27.2$ & 0.897 & $32.9 \pm 20.9$ & $31.9 \pm 26.4$ & 0.882 & $45.6 \pm 27.2$ & $45.2 \pm 26.9$ & 0.962 \\
\hline Pathology & $53.3 \pm 28.1$ & $39.1 \pm 23.8$ & 0.010 & $39.9 \pm 26.3$ & $32.7 \pm 22$ & 0.312 & $67.3 \pm 22.9$ & $45.7 \pm 24.2$ & 0.004 \\
\hline Pharmacology & $46.4 \pm 30.4$ & $54 \pm 27.8$ & 0.215 & $31.4 \pm 23.9$ & $50.8 \pm 28$ & 0.015 & $62.1 \pm 28.9$ & $57.3 \pm 27.9$ & 0.571 \\
\hline Microbiology & $50.3 \pm 29.2$ & $54 \pm 25$ & 0.520 & $33.6 \pm 22.2$ & $51.9 \pm 27.7$ & 0.017 & $67.8 \pm 25.4$ & $56.1 \pm 22.2$ & 0.106 \\
\hline Parasitology & $40.6 \pm 24.6$ & $36.8 \pm 20.5$ & 0.432 & $32.7 \pm 22.6$ & $32.7 \pm 20.8$ & 0.998 & $48.8 \pm 24.5$ & $41.2 \pm 19.6$ & 0.251 \\
\hline Total & $45.2 \pm 28.8$ & $43.2 \pm 27.8$ & 0.736 & $28.3 \pm 17.2$ & $38.3 \pm 27.8$ & 0.152 & $62.9 \pm 28.1$ & $48.3 \pm 27.4$ & 0.085 \\
\hline
\end{tabular}

Data are presented as mean \pm standard deviation.

a) Students were divided into two groups based on the median score in "understanding human responses" course, which they took in previous semester.

${ }^{\mathrm{b})} \mathrm{By}$ independent sample t-test. 
except for a decrease in the pathology score (Table 5). However, when we divided 2018M3 into high achiever (HA) and low achiever (LA) groups, a significant improvement in achievement was observed in the LA groups $(\mathrm{p}=0.015)$. Additionally, a similar trend was observed in microbiology $(\mathrm{p}=0.017)$.

\section{Discussion}

This study demonstrated that teaching pharmacology primarily with TBL was generally well accepted by medical students, with the exception of their individual preparatory burdens for iRAT. Compared to their individual scores, however, students showed significantly improved performance at the group level. More importantly, the delayed learning outcome demonstrated in a nationwide test suggested that improvement in pharmacology learning through a TBL course has a lasting effect, especially for LAs compared to HAs.

\section{Immediate outcomes: students' reactions and learning during the course}

Evaluation of participants' reactions to education programs, the first step in Kirkpatrick's four-level evaluation model, is conducted most frequently owing to its simple implementation. Although reaction is noted to be weak in its association with higher level outcomes such as learning or transfer, in some situations it can be as important as the other evaluation targets [21]. Furthermore, provided that learners' emotions are closely related to their subsequent decisions and behaviors [22,23], positive reactions would be expected to stimulate learning and change behavior.

Therefore, it is encouraging that students' reactions were generally positive, especially since our TBL course was added on to the existing curriculum as a substitute for self-study week. The students' judgment of the positive utility of TBL could be one significant reason for this. As Tables 3 and 4 show, both their subjective perception and the actual test results support that TBL sessions provided an explicit benefit for studying clinical pharmacology. Furthermore, it is also noteworthy that the students evaluated group members as being active and collaborative participants, considering that the evaluation of reaction increasingly emphasizes the degree of engagement as well as the relevance of the contents [24].

By contrast, in the post-course survey, items concerning pre-class preparation and in-class iRAT difficulty were rated most negatively. Considering the comments that students struggled to comprehend clinical knowledge, this negative perception may be related to the iRAT/gRAT items, all of which included clinical vignettes. This is consistent with the systemic review of TBL, which indicated that an increased workload often acts as a risk factor of poor learner satisfaction [11]; that is, while students acknowledge that TBL is helpful with respect to the outcomes, but they also find the process to be a burden.

Nevertheless, aside from these conflicting responses, the students seemed to have achieved a substantial portion of the expected learning outcomes of the course through TBL. The average of the gRAT score, twice that of iRAT, substantiates this notion. The AT scores in each group also showed significant improvement over the iRAT average, although they were lower than the gRAT scores. Thus, despite students' subjective perceptions of the high difficulty of iRAT, with adequate support, it is considered to be in the range of their abilities.

The assumption that most students participated equally in team activities regardless of their preparedness is also supported by the fact that the iRAT scores showed no significant correlation with the peer evaluation scores. 
Indeed, in the open-ended question in the post-course survey, one of the most common themes was the difficulty in peer evaluation of finding differences between peers, i.e., "It is so difficult to discriminate among group members, because all the members worked so hard. I feel sorry for them." In brief, it seems that most students diligently participated in TBL, and this active participation of the majority may have led to the effect of TBL promoting improvement in performance both at the individual and group levels [13].

\section{Delayed outcomes: student achievement in Comprehensive Basic Medical Sciences Examination}

Despite our positive immediate outcomes, the gRAT scores collected through TBL have inherent limitations for judging the improvement of learning. As a shortterm achievement at the group level, the high gRAT scores may not necessarily guarantee a long-term effect of TBL or the improvement of individual group members. Therefore, we analyzed the results of the CBMSE, administered about 4 weeks after the end of the course, to examine improvements in pharmacological learning at the individual level. The result suggested that TBL had a more pronounced effect on low academic achievers; that is, unlike the previous year's cohort (2017M3), which completed the same curriculum with the exception of ICP, there was no significant change in the CBMSE pharmacology percentile rank of the entire 2018M3 and HA group; significant improvement was only found among LA group. This difference in performance between LA and HA is consistent with previous studies, in which TBL was applied to biomedical courses in premedical curricula [17] or pathology learning in second-year medical curricula [13].

Why was the effect more salient in the LA group? One possible explanation is that TBL resulted in "no burdensome duty (being) placed on higher performing students" [13]. However, this does not necessarily imply that TBL is meaningless to high-ranking students. As with previous reports [10], in our study, even the lowest gRAT score was higher than the highest iRAT score. Moreover, HA who taught their LA peers tended to reinforce their own learning by reaffirming their understanding and retrieving knowledge while teaching their colleagues. More importantly, this process may also have improved other cognitive as well as noncognitive skills, including critical thinking and communication skills, which could help students acquire advanced knowledge in the future [25]. Notwithstanding these advantages, at least in the short term, the process itself may not have directly contributed to the instant acquisition of more advanced knowledge. Another explanation could be the limited items used in our AT. It is possible that the question items used did not represent a suitable method for stimulating or further advancing the pharmacological knowledge of HA students. The primary aim of a standardized, high-stake assessment such as KMLE lies in the assessment of learning rather than individualized, formative assessment for learning [26]. Thus, our result could be attributable to the limitations of the item bank that we used (i.e., CBMSE, CCMSE, and KMLE) in the TBL sessions.

\section{Practical implications and limitations}

Based on the major findings of this study, two implications can be derived. The first is the need for adequately challenging tasks to foster the acquisition of essential knowledge. To achieve the intended learning objectives, it seems better to use "somewhat burdensome" tasks for advanced preparation material and iRAT, although this may cause negative reactions in students. This is also reasonable from the perspective of competency-based medical education (CBME). There are 
concerns that if CBME is improperly embedded, it may mistakenly "emphasize the bare minimum or lowest common denominator [27]," or lead to "demotivation, a focus on minimal acceptable standards, $(\cdots)$ and a reduction in the educational contents [28]." Therefore, it would be desirable to assign challenging tasks at the cost of student satisfaction to maximize the effectiveness of TBL.

The second implication is the need for appropriate tasks to promote the advancement of HA students. Research has constantly confirmed TBL as an effective strategy in acquiring knowledge, and the focus of attention is shifting from simple knowledge to higherlevel learning outcomes [11]. While the acquisition of simple knowledge is meaningful for LA students, HA students who already have a sufficient knowledge foundation would see TBL as more beneficial when it explicitly aims to improve the development of advanced knowledge and skills.

There are several limitations to this study. First, the generalization of the study may be limited in that it targeted a single cohort in a medical school. However, our data sufficiently represent the whole class, given that there were no students missing in the data collection. Second, our research design, which compared the cohort that completed the TBL course with students who had a self-study week-essentially a non-intervention comparison group is another limitation [29]. The improvement of CBMSE scores in the 2018M3 cohort may be confounded by the effect of the increased total amount of pharmacology education due to the new ICP course, although our data showed a discriminatory result between the LA and HA groups, consistent with earlier studies. Finally, the findings show significant CBMSE score increases, not only in pharmacology but also in microbiology. This seems to be attributable to pharmacology-related areas such as antibiotics. Never- theless, further study may be required to investigate the effect of the introduction of TBL at the broader curricular level, including the positive and negative influence on study in other courses.

In conclusion, our study supports that organizing a course primarily based on TBL is an effective way of teaching pharmacology to medical students. Especially, it seems to be more beneficial for low-achieving than high-achieving students. While the perceived burden of the pre-class material may slightly lower students' satisfaction, based on our findings, we recommend the use of challenging tasks to maximize the effect of TBL.

\section{ORCID:}

Do-Hwan Kim: https://orcid.org/0000-0003-4137-7130; Jung-Ho Lee: https://orcid.org/0000-0003-3268-8332; Soon Ae Kim: https://orcid.org/0000-0002-9831-0511

Acknowledgements: We would like to appreciate all the students and facilitators who actively participated in the course for the whole semester. This study is supported by the Center for Teaching and Learning of Eulji University.

\section{Funding: None.}

Conflicts of interest: No potential conflict of interest relevant to this article was reported.

Author contributions: SAK conceived the initial design of the study and DHK drafted the manuscript. DHK, JHL, and SAK collected, analyzed, and interpreted the data. All authors read, critically reviewed, and approved the final manuscript.

\section{References}

1. Woods NN, Neville AJ, Levinson AJ, Howey EH, Oczkowski WJ, Norman GR. The value of basic science 
in clinical diagnosis. Acad Med. 2006;81(10 Suppl): S124-S127.

2. Kulasegaram KM, Martimianakis MA, Mylopoulos M, Whitehead CR, Woods NN. Cognition before curriculum: rethinking the integration of basic science and clinical learning. Acad Med. 2013;88(10):1578-1585.

3. Kulasegaram K, Manzone JC, Ku C, Skye A, Wadey V, Woods NN. Cause and effect: testing a mechanism and method for the cognitive integration of basic science. Acad Med. 2015;90(11 Suppl):S63-S69.

4. Dolmans D, Michaelsen L, van Merriënboer J, van der Vleuten C. Should we choose between problem-based learning and team-based learning? No, combine the best of both worlds! Med Teach. 2015;37(4):354-359.

5. Haramati A. Educating the educators: a key to curricular integration. Acad Med. 2015;90(2):133-135.

6. Parmelee D, Michaelsen LK, Cook S, Hudes PD. Teambased learning: a practical guide: AMEE guide no. 65 . Med Teach. 2012;34(5):e275-e287.

7. White C, Bradley E, Martindale J, et al. Why are medical students 'checking out' of active learning in a new curriculum? Med Educ. 2014;48(3):315-324.

8. Varpio L, Bell R, Hollingworth G, et al. Is transferring an educational innovation actually a process of transformation? Adv Health Sci Educ Theory Pract. 2012;17(3): 357-367.

9. Burgess AW, McGregor DM, Mellis CM. Applying established guidelines to team-based learning programs in medical schools: a systematic review. Acad Med. 2014; 89(4):678-688.

10. Parmelee DX, Michaelsen LK. Twelve tips for doing effective team-based learning (TBL). Med Teach. 2010; 32(2): 118-122.

11. Fatmi M, Hartling L, Hillier T, Campbell S, Oswald AE. The effectiveness of team-based learning on learning outcomes in health professions education: BEME guide no. 30. Med Teach. 2013;35(12):el608-el624.
12. Levine RE, Hsieh P, Kelly PA, et al. The facilitator instrument for team-based learning (FIT). Teach Learn Med. 2020;32(1):82-90.

13. Koles PG, Stolfi A, Borges NJ, Nelson S, Parmelee DX. The impact of team-based learning on medical students' academic performance. Acad Med. 2010;85(11):17391745.

14. Zgheib NK, Dimassi Z, Bou Akl I, Badr KF, Sabra R. The long-term impact of team-based learning on medical students' team performance scores and on their peer evaluation scores. Med Teach. 2016;38(10):1017-1024.

15. Bou Akl I, Ghaddar F, Sabra R, et al. Teaching clinical pharmacology using team-based learning: a comparison between third- and fourth-year medical students. J Clin Pharmacol. 2012;52(12):1806-1814.

16. Zgheib NK, Simaan JA, Sabra R. Using team-based learning to teach clinical pharmacology in medical school: student satisfaction and improved performance. J Clin Pharmacol. 2011;51(7):1101-1111.

17. Mun KH, Mun KC. Verification of learner's differences by team-based learning in biochemistry classes. Korean J Med Educ. 2017;29(4):263-269.

18. Park KD, Kim B, Kim T, Phyo S, Myung SJ. Is remediation program using team-based learning effective for at-risk medical students? Korean J Med Educ. 2014; 26(1):25-29.

19. Cianciolo AT, Regehr G. Learning theory and educational intervention: producing meaningful evidence of impact through layered analysis. Acad Med. 2019;94(6):789 794.

20. Elo S, Kyngäs $H$. The qualitative content analysis process. J Adv Nurs. 2008;62(1):107-115.

21. Cook DA. Twelve tips for evaluating educational programs. Med Teach. 2010;32(4):296-301.

22. LeBlanc VR, McConnell MM, Monteiro SD. Predictable chaos: a review of the effects of emotions on attention, memory and decision making. Adv Health Sci Educ 
Theory Pract. 2015;20(1):265-282.

23. Van de Ridder JM, Peters CM, Stokking KM, de Ru JA, Ten Cate OT. Framing of feedback impacts student's satisfaction, self-efficacy and performance. Adv Health Sci Educ Theory Pract. 2015;20(3):803-816.

24. Moreau KA. Has the new Kirkpatrick generation built a better hammer for our evaluation toolbox? Med Teach. 2017;39(9):999-1001.

25. Azer SA, Guerrero AP, Walsh A. Enhancing learning approaches: practical tips for students and teachers. Med Teach. 2013;35(6):433-443.

26. Lockyer J, Carraccio C, Chan MK, et al. Core principles of assessment in competency-based medical education. Med Teach. 2017;39(6):609-616.

27. Tekian A, Hodges BD, Roberts TE, Schuwirth L, Norcini J. Assessing competencies using milestones along the way. Med Teach. 2015;37(4):399-402.

28. Leung WC. Competency based medical training: review. BMJ. 2002;325(7366):693-696.

29. Cook DA. If you teach them, they will learn: why medical education needs comparative effectiveness research. Adv Health Sci Educ Theory Pract. 2012; 17(3):305-310. 